原著

\title{
兩側の血行再建を行った内頸動脈狭窄症 一頸動脈ステント留置の活用一
}

$\begin{array}{cccc}\text { 川端 } & \text { 康弘, 永田 泉, 坂井 信幸, 中原一郎 } \\ \text { 下鶴 哲郎, 酒井 秀樹, 東 登志夫, 高橋 淳 } \\ \text { 大田 元, 菊池 晴彦 }\end{array}$

\section{Treatment of Bilateral Internal Carotid Artery Stenosis}

Yasuhiro Kawabata, M.D., Izumi Nagata, M.D., Nobuyuki SakaI, M.D., Ichiro NAKaHARA, M.D., Tetsuro ShimozUru, M.D., Hideki SAKaI, M.D., Toshio Higashi, M.D., Jun C. Takahashi, M.D., Hajime OHTA, M.D., and Haruhiko KIKUCHI, M.D.

Department of Neurosurgery, National Cardio-vascular Center, Kyoto, Japan

\section{Key words:}

- bilateral carotid stenosis

- carotid endarterectomy

- carotid angioplasty and stenting

Surg Cereb Stroke

(Jpn) 29: 339-344, 2001

\section{はじめに}

高度の内頸動脈狭窄症に関するNASCE ${ }^{10)}$ (North American Symptomatic Carotid Endarterectomy Trial),
(Executive Committee for the Asymptomatic Carotid Atherosclerosis Study)により内科的治療に対する外科的 治療の優位性が認められ，血行再建術として頚動脈内 膜剝離術 (CEA)が・般的に行われているが，対側䫫動脈

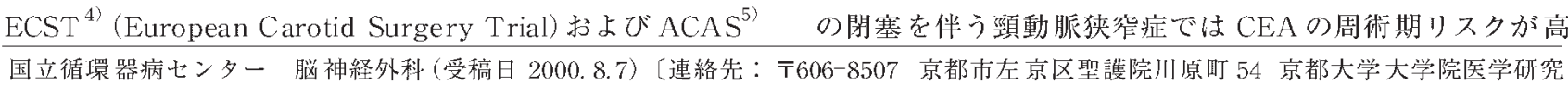
科脳神経外科 川端康弘] [Mailing address: Yasuhiro Kawaba TA, M.D., Department of Neurosurgery, University of Kyoto, Graduate School of Medicine, 54 Kawahara-cho, Shogoin, Sakyo-ku, Kyoto, Kyoto 606-8507, Japan] 
いことが知られている，両側内䫁動脈が高度狭窄を示す症 例に㧍いても術前検査で脳血流の低下を示すことが多く，

·側の覑動脈を比較的長時間遮断する必要がある CEAで は治療に難渋することが少なくない。・方低侵襲治療とし て近年急速に発展してきたステント留置術 (carotid angioplasty and stenting. CAS) ${ }^{2) 16)} は$ distal protective balloon ${ }^{15)}$ の使用により CEAに匹敵するような治療成績をあ げられるようになった。著者らはステント留置術導人後の 当科に打ける経験から，両側頚動脈狭窄症に対して積極的 にCASを応用してきたのでその方針と結果を報告する。

\section{対象と方法}

1997 年 12 月から 2000 年 3 月までに当科にて血行再建術 の適応となった颈動脈狭窄症は83例（男72例, 女 11 例, 平均 70.0 歳), 91 病変で, これに対L CEA を 45 例 46 病変 で, CASを 45 例 48 病変で行った。このうち両側の治療を 要した 8 例 (男性 8 例, 平均 68.4 歳) を検討の対象とした。 両側無症候性钼動脈狭窄症は2 例であった。

術前術後に頸部エコーにより狭窄の程度や plaque の性 状の把握を行い, echolucent, echogenic, mixed, calcified typeに分類した。8例中の 5 例でPET, 残りの3 例で SPECTによる脳循環動態の把握を行った。測定法につい ては, PETは ${ }^{15} \mathrm{O}$-gas 吸入法を, SPECTは ${ }^{123}$ I-IMP ARG 法を用いた。PETでは Powersら ${ }^{11)}$ の血行力学的分類に従 い, Stage $0 \sim 2$ に分類した. Stage 0 は血行力学的に正常 で, CBF (cerebral blood flow)/CBV (cerebral blood volume)が $10.7 \mathrm{~min}^{-1}$ (当施設 mean-1SD) 以上とした。 Stage 1 は脳血管床の代償的拡張期で, $\mathrm{CBF} / \mathrm{CBV}$ が $10.7 \mathrm{~min}^{-1}$ 未满から OEF (oxygen extraction fraction) が $52 \%$ 未满とした。 Stage 2 は貧困灌流の状態で, $\mathrm{CBF} / \mathrm{CBV}$ が $10.7 \mathrm{~min}^{-1}$ 未满から $\mathrm{OEF}$ が $52 \%$ 以とし た.SPECTでは安静時 CBF と acetazolamide $1 \mathrm{~g}$ 負荷後 のCBF 测定し脳循環予備能 (cerebrovascular reserve: CVR (\%)) を求めた。血行力学的正常群 $(\mathrm{CVR} \geqq 30 \%)$ を Sta ge A, 脳循環予備能低下. 血流正常群 (CVR $<30 \%$ 名 つBF $\geqq 30 \mathrm{ml} / \mathrm{min} / 100 \mathrm{ml})$ をStage $\mathrm{B}$, 脳循環予備能が 高度に低下しているか品失して㧍り血流が低下している群 $(\mathrm{CVR}<20 \%$ から $\mathrm{CBF}<30 \mathrm{ml} / \mathrm{min} / 100 \mathrm{ml})$ をStage Cと した。狭窄度の評価にはNASCET法を用いた。頸動脈狭 窄症に対しては, 個々の症例に扮いて術前の患者の全身状 態, 年齢, 全身状態, 臨床症状, プラークの性状, collateral circulation(脳血流)を十分考虑して治療方針を決定し た。CEAは経鼻挿管下に全身麻酔で行い, 術中の内シャ ントはstump pressureが著しく低いときあるいはSEPの 異常が生じたときに選択的に用いる方針で臨んでいるが, 内シャントは用いなかった。CASは局所麻酔下に大腿動
Table 1 Patient characteristics

\begin{tabular}{cccc}
\hline No. & Sex & Age & Medical history \\
\hline 1 & $M$ & 66 & HTN, DM, HL \\
2 & $M$ & 63 & HTN, DM, HL, sm, MI \\
3 & $M$ & 69 & $H T N, D M, H L$, sm, ASO, Af \\
4 & $M$ & 71 & - \\
5 & $M$ & 63 & DM, CABG \\
6 & $M$ & 68 & DM, HL \\
7 & $M$ & 64 & dysrhythmia, DU, sm \\
8 & $M$ & 66 & DM, HL, sm \\
\hline
\end{tabular}

$\mathrm{HTN}=$ hypertension, $\mathrm{DM}=$ diabetes mellitus, $\mathrm{HL}=$ hyperlipidemia, $\mathrm{sm}=$ smoking, $\mathrm{Ml}=$ myocardial infarction, $\mathrm{CABG}=$ coronary artery bypass graft, $\mathrm{DU}=$ duodenal ulcer, $\mathrm{ASO}=$ arteriosclerosis obliterans, $\mathrm{Af}=$ atrial fibrillation

脈経由で行い, 1998年 11 月までは balloon-expandable typeの Palmaz stent を用いていたが，その後 self-expandable stentに切り替え,また1999年 3 月以降は後拡張の際 に distal protective balloonを導人し, 初期の症例 1,5 を 除く6症例にこれを用いた。またCAS，CEAともに術後 2-5 П目に拡散強諷画像 (Diffusion-weighted Image; DWI) を含わた MRIを施行し，新たな急性期の棵塞巣の検索を 行った。周術期の虚血性合併症は術後 30 П以内に生じた ものとした。

\section{結＼cjkstart果}

患者 8 例のうち, 高血圧を 3 例, 糖尿病を 6 例, 高脂血 症を 5 例, 喫煙歴を 4 例に認め, 冠動脈のバイパス術後の 患者が 1 例であった (Table 1)。16 病変の狭察率は 50-99\% (平均 84\%) で, 症例 7 を除く 7 例で両側 $70 \%$ 以上の高度狭 窄を示した (Table 2)。超音波によるプラークの性状は echolucent-7, echogenic-2, mixed-4, calcified-3であった。 その内䚿は, 症候性のプラータで echolucent-4, mixed-1, calcified-1であり，一方無症候性のプラータで echolucent3, echogenic-2, mixed-1, calcified-4であった。PETを 施行した 5 例で両側とも正常範囲であったのが 1 例, 片側 が正常で対側が Stage 1であったのが2例，両側ともに Stage 1であったのが2例であった. SPECTを施行した 3 例では，いずれも片侧が Stage A で反対㑡がStage Bであ った、行った治療は 3 種類で, 一㑡のCAS 後に対側の CEAを 4 例に, 両㑡の CASを 3 例で, 両側の CEAを 1 例 で行った。すべての病変で, 治療後十分な血管拡張が得ら れた。周術期合併症に関しては, CAS 後にCEAを行った 1 例で CEA 後に一過性の失語を認め, 両側 CAS 群で・過 性の左片麻瘏を認めたが, 永続的な脳虚血症状を呈したも のはなかった。また, 両側 CAS 群の1例で, 臨床症状を 呈さずに術後 DWIにて high intensityを認めた。 
Table 2 Clinical pictures of the patients of bilateral ICS

\begin{tabular}{|c|c|c|c|c|c|c|c|c|}
\hline No. & Side & Symptoms & Diagnosis & Other lesion & Duplex & Hemodynamics & Procedure & Complication \\
\hline \multirow[t]{2}{*}{1} & $R$ & & rt ICS (95) & & echolucent & stage 1 & (2)CEA & (2)transient aphasia \\
\hline & $L^{*}$ & it hemiparesis & It ICS $(95)^{*}$ & & echolucent* & stage $1^{*}$ & (1)stent (Easy Wall)* & (1)none \\
\hline \multirow[t]{2}{*}{2} & $R^{*}$ & It hemiparesis & rt ICS $(90)^{*}$ & & calc $^{*}$ & stage $O^{*}$ & (2)CEA* & (2)none \\
\hline & L & & It ICS (90) & & calc & stage 1 & (1) stent (smart) & (1)none \\
\hline \multirow[t]{2}{*}{3} & $R^{*}$ & It upper quadrianopsia & $\operatorname{rt} \operatorname{ICS}(70)^{*}$ & & mixed* & stage $1^{*}$ & (1)stent (smart)* & (1)none \\
\hline & $L^{*}$ & it hemiparesis & It ICS (99)* & It sub stenosis & echolucent* & stage 1 * & (2) CEA* & (2)none \\
\hline \multirow[t]{2}{*}{4} & $R^{*}$ & amaurosis fugax & $\operatorname{rt} \operatorname{ICS}(95)^{*}$ & & echolucent* & stage $\mathrm{O}^{*}$ & (1) stent (smart)* & (1)none \\
\hline & L & & It ICS (99) & & echolucent & stage 1 & (2)CEA & (2)none \\
\hline \multirow[t]{2}{*}{5} & $R$ & & rt ICS (70) & it VA stenosis & calc & stage $A$ & (2) stent (smart) & (2)none \\
\hline & L & & It ICS (90) & It sub stenosis & calc & stage B & (1)stent (smart) & (1)DWI high lesion \\
\hline \multirow[t]{2}{*}{6} & $R$ & & rt ICS (70) & & echogenic & stage $A$ & (1)stent (smart) & (1)none \\
\hline & $L$ & & It ICS (75) & & echogenic & stage B & (2)stent (smart) & (2)none \\
\hline \multirow[t]{2}{*}{7} & $R^{*}$ & It hemiparesis & $\operatorname{rt} \operatorname{ICS}(60)^{*}$ & it $\vee A$ occ & echolucent* & stage $B^{*}$ & (1) stent (palmaz)* & (1)transient It hemiparesis \\
\hline & L & & It ICS (50) & It $\vee A$ occ & echolucent & stage A & (2)stent (smart) & (2)DWI high lesion \\
\hline \multirow[t]{2}{*}{8} & $R$ & & rt ICS (95) & & mixed & stage 0 & (2)CEA & (2)none \\
\hline & $L^{*}$ & amaurosis fugax & $\operatorname{lt} \operatorname{ICS}(95)^{*}$ & & mixed* & stage 0 & (1)CEA* & (1)none \\
\hline
\end{tabular}

sub = subclavian artery, occ. $=$ occlusion, DWI=diffusion weighted image, calc $=$ calcified, ${ }^{*}$ indicate symptomatic sides.

The figures in parenthesis mean the degrees of carotid stenoses.

(1) mean first procedures, and (2) mean second procedures
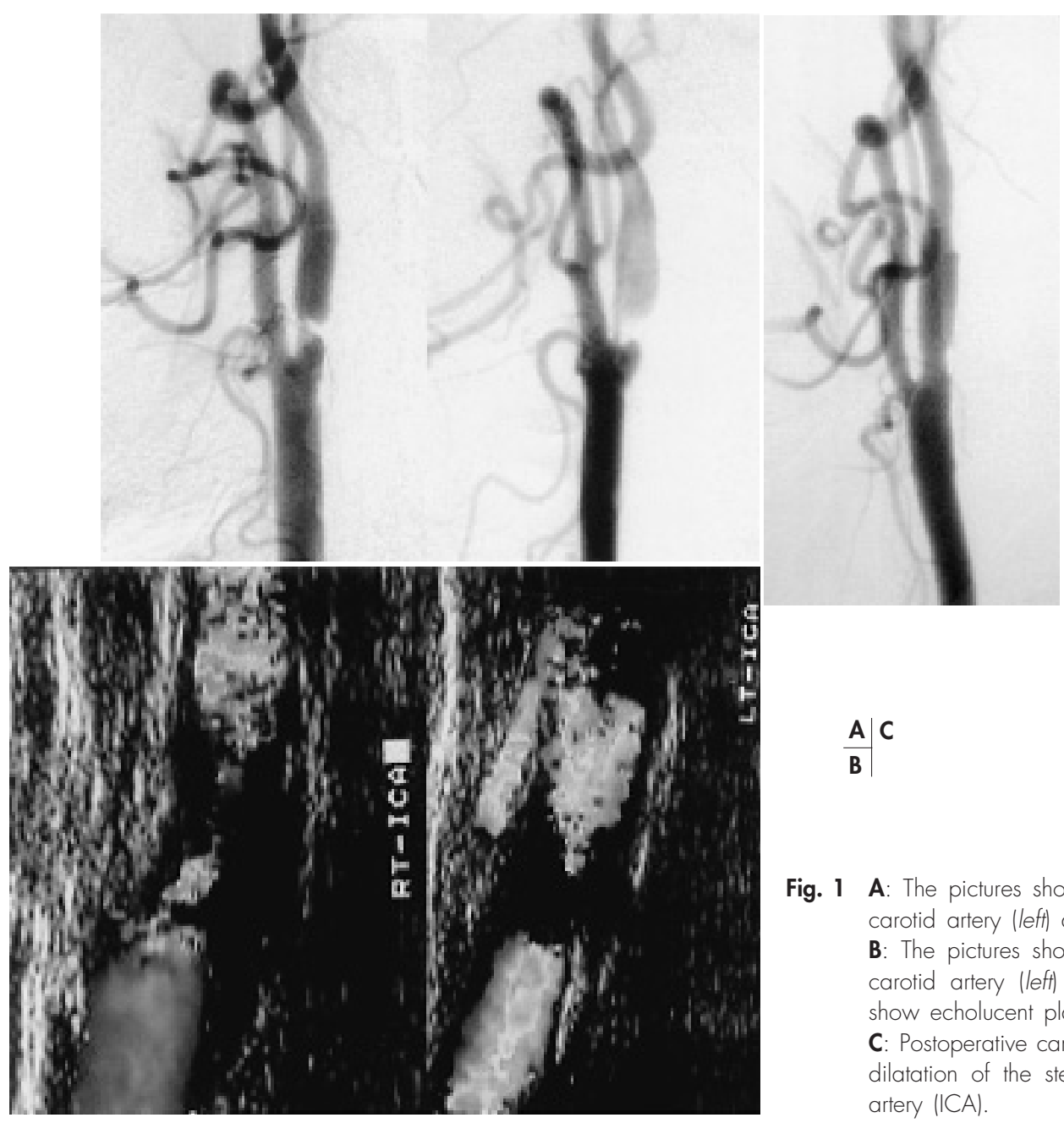

Fig. 1 A: The pictures show preoperative angiography of right carotid artery (leff) and, left carotid artery (right).

B: The pictures show color-doppler echography of right carotid artery (left) and left carotid artery (right). They show echolucent plaques of both of the carotid arteries. C: Postoperative carotid arteriography showing adequate dilatation of the stenotic lesion of right internal carotid artery (ICA). 

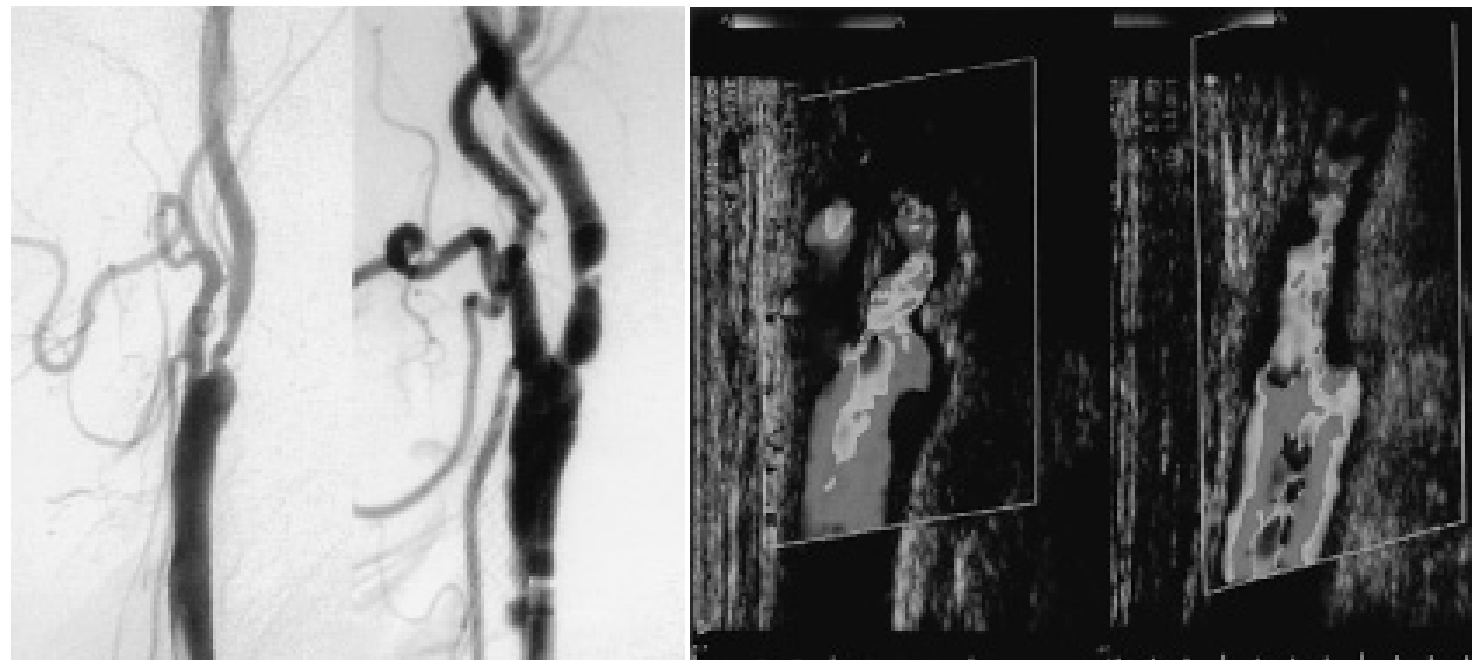

Fig. 2 A: Preoperative carotid arteriography (leff) shows severe stenosis of the right ICA. Preoperative carotid arteriography (right) shows severe stenosis of left ICA.

B: Color-doppler echography (leff) shows the right carotid artery stenosis and the echogenic

A $\mid \mathbf{B}$ plaque. Color-doppler echography (right) shows the left carotid artery stenosis and the echogenic plaque.

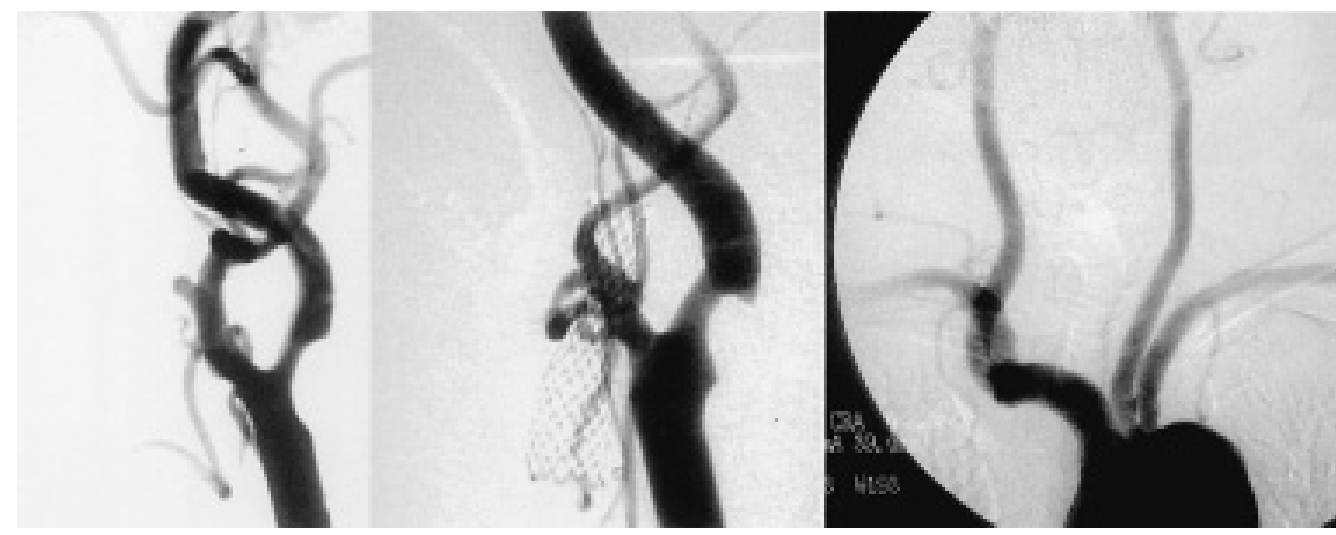

Fig. 3 Preoperative right CAG (leff) and left CAG (central) show moderate stenosis of bilateral carotid arteries. Preoperative aortography (right) shows total occlusion of bilateral vertebral arteries at the origin.

以下に代表症例をあげる。

〈症例 4〉 71 歳, 男性. 左眼の.過性黒内障にて発症し た. 左内钼動脈の $99 \%$ 狭窄孔よび右内钼動脈の $95 \%$ 狭窄 であった(Fig. 1A)。脳血流検査では両側とも脳血流は保 たれていたものの, 脳循環予備能は低下していた。両侧と も echolucent なプラークであったが(Fig. 1B)，まず無症 状側の右内顓動脈に対して CASを行い(Fig. 1C), その後 左内湏動脈のCEA を行った。CAS 後にDWIにて右頭頂 葉に high intensity areaを認めたが, 全経過中虚血症状な く経過した。

〈症例 6〉68歳, 男性. 無症状であったが, MRA打よ び頸部エコーにて両側内頸動脈狭窄症と診断された (Fig.
2A，B)・プラークの性状は両側とも echogenic typeであ った。両侧のCASを行い, 合併症なく経過した。

〈症例 7〉 64 歳, 男性. 左片麻瘒㧍よび左半盲を伴い, 意識消失発作にて発症した。頭部 CT およびMRIにて右 半球に広範な梗塞を認めた。脳血管撮影では両側内頸動脈 は狭窄しており，両側椎骨動脈は完全閉塞していた（Fig. 3）、狭窄度は50-60\%と中等度であったが, collateral circulationが不良であるので両侧内钼動脈のCASを施行し た。

考察

頖動脈狭窄症に対しては $\mathrm{CEA}{ }^{4>5) 10)}$ が・般的に行われ 


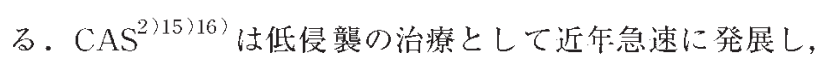
high risk患者を中心として広く行われるようになった。 現在米国に扔いて多施設でのCEA と CASの prospective randomized trial(Carotid Revascularization Endarterectomy Versus Stent Trial: CREST)が始まるところであ りその結果は大いに注目されている。著者らの distal pro tective balloonを使用したCAS 連続 120 例に扔ける合併 症は $2.5 \%$ (major stroke 1, minor stroke 2, death 0)で あり，CEAと同等またはそれ以下である。したがって著 者らは, 頙動脈狭窄症に対して, CEAになんらかのリス クのありCASに利点がある場合には, 積極的にCASを行 う方針としている。

CASの. 一番の問題点は distal embolism ${ }^{1)}$ である. 表面 に潰瘍や内膜下に出血を伴う脂質に富むプラータは, 塞栓 を生じ症状を呈しやすいという報告がある7713)14). 一方, 頸部エコーの所見とプラークの病理学的所見の関連がいわ $れ^{8)}$, echolucentのものは脂肪組織や出血を, echogenic のものは繊維組織を, acoustic shadowを引くものは石灰 化を示すとされている．著者らは，エコー所見でecholucent あるいはmixed なプラータは脂肪や出血を多く含む ために不安定であり，血管の内腔を押し広げるCASでは 特に注意が必要と考えている。Qureshi ${ }^{12)} ら は \operatorname{CAS} の$ 周 術期合併症の危険因·ととし, 症候性のプラーク, 高コレ ステロール血症のないもの, 狭窄部位の長さをあげている が，CASの施行にあたって危满な病変を予测することは 今後の研究課題である.

両側内頸動脈に狭窄を伴う症例では・侧または両侧に血 行力学的異常を呈することが多く, 一側の内顐動脈の遮断 する必要がある CEA では注意が必要である。実際, 対側 钼動脈閉塞を伴う钼動脈狭窄症に対する CEA は, NASCE T ${ }^{10)}$ その他の報告でも, 周術期合併症が高いこと

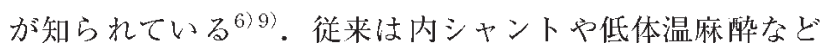
の対策がとられてきた。当科では術中のモニターを参考に 選択的に内シャントをする方針であるが，内シャントを置 くことは手技が煩雑になりこれ自体の危険もないとはいえ ない。また両側のCEAを行うことは患者にとっても負担 が大きい。著者らは両側内頸動脈狭窄症に対して, 4 例で

一㑡のCASを行った後対側のCEAを行い， 3 例で両侧の CAS を施行し, 永続的な神経学的合併症はなく良好な成 績を得た。側のCASに関しては, 初期の症例 1 を除い て, 症状侧, プラータのエコー所見, 狭窄度を考虑し, CASのリスクが相対的に低いと考元られる侧（無症候・ echogenic ・狭窄度が軽い)にCASを行ったのち,リスタ が高い側の CEAを行った。両側無症状で頸部エコー所見 でも echogenic plaqueであるときや, 椎骨脳底動脈系を 含む主幹動脈の多枝病変であるときには両側のCASを行
った。症例 8ではプラークが両侧とも mixedであるので CASのリスクが高いと考えられ，全身合併症がなく脳血 流検査で両側とも血行力学的に正常に保た机ていたため両 側の CEAを施行した。

信頼できるCEAとCASの比較を行うには randomized trialの結果を待ななければならないが，両側に高度の狭 窄を有する頸動脈狭害症では・側または両側のCASは有 効な治療になりうると考えられた。今後さらに症例を積み 重ねて, 年齢, 症状の有無, collateral circulation, 靧部 エコーなどによるプラータの性状の正確な評価により治療 方針を決定していく必要がある。また，CASは長期成績 についていまだ不明な点があり，再狭窄をきたす可能性が

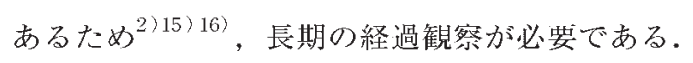

\section{結語}

両側内钼動脈狭窄症では脳血流が低下していることが多 い. 頸動脈狭窄症に対する血行再建術としてCEAが・般 的に行われるが, CEAでは術中に血行を遮断する必要が あるために注意が必要である。術前に患者の全身状態，年 齢, プラータの性状, 症状側, collateral circulation(脳血 流）を十分考慮して治療方針を決定すべきである。著者ら は積極的にCASを導人し著しく䎹らかいプラータを除け ば自し拡張型ステントと protective balloonの応用により 比較的安全に治療を行うことが可能になった。両側に高度 の狭窄を有する貿動脈狭窄症では・側または両側のCAS は有効な治療になりうると考えられるが, 今後症例の積み 重ねと長期の経過観察が必要である。

\section{文献}

1) Crawley F, Clition A, Buckenham T, et al: Comparison of hemody namic cerebral ischemia and microembolic signals detection during carotid endarterectomy and carotid an gioplasty. Stroke 28: 2460-2464, 1997

2) Diethrich $\mathrm{EB}$, et al: Stenting in the carotid artery: initial experience in 110 patients. J Endovasc Surg 3: 42-62, 1996

3) Eliasziw M, Streifler JY, Fox AJ, et al: Significance of plaque ulceration in symptomatic patients in symptomatic patients with high-grade carotid stenosis Stroke $\mathbf{2 5}$ 304-308, 1994

4) European Carotid Surgery Trialists' Collaborative Group: MRC European Carotid Surgery Trial: interim results for symptomatic patients with severe $(70-99 \%)$ or with mild (0-29\%) carotid stenosis Lancet 337: 1235-1243, 1991

5) Executive Committee for the Asymptomatic Carotid Atherosclerosis Study: Endarterectomy for asymptomatic carotid artery stenosis. JAMA 273: 421-1428, 1995

6) Gasecki AP, Eliasziw M, Ferguson GG, et al: Long-term prognosis and effect of endarterectomy in patients with symptomatic severe carotid stenosis or occlusion: results from NASCET. J Neurosurg 83: 778-782, 1995

7) Golledge J, Greenhalgh RM, Davies AH: The symptomatic carotid plaque. Stroke 31: 774-781, 2000 
8) Kagawa R, Moritake K, Shima T, et al: Validity of B-mode ultrasonographic findings in patients undergoing carotid endarterectomy in comparison with angiographic and clinicopathologic features. Stroke 27: 700-705, 1996

9) McCarthy WJ, Wang R, Pearce WH, et al: Carotid endarterectomy with an occluded contralateral carotid artery. Am J Surg 166: 168-171, 1993

10) North American Symptomatic Carotid endarterectomy Trial Collaborators: Beneficial effect of carotid endarterectomy in symptomatic patients with high-grade carotid stenosis N Engl J Med 325: 445-453, 1991

11) Powers WJ, Press GA, Grubb RL, et al: The effect of hemody namically significant carotid artery disease on the hemodynamic status of the cerebral circulation. Ann Intern Med 106: $27^{-} 35,1987$

12) Qureshi AI, Luft AR, Janardhan V, et al: Identification of patients at risk for periprocedural neurological deficits associated with carotid angioplasty and stenting. Stroke 31: $376^{-} 382,2000$

13) Rothwell PM, Gibson R, Warlow CP: Interrelation between plaque surface morphology and degree of stenosis on carotid angiograms and the risk of ischemic stroke in patients with symptomatic carotid stenosis. Stroke 31: $615-621,2000$

14) Seeger JM, Barratt E, Lawson GA, et al: The relationship between carotid plaque composition, plaque morphology, and neurologic symptoms. J Surg Res 58: 330-336, 1995

15) Theron JG, Payelle GG, Coskun O, et al: Carotid artery stenosis treatment with protected balloon angioplasty and stent placement. Radiology 201: 627-636, 1996

16) Wholey MH, Wholey M, Bergeron P, et al: Current global status of carotid artery stent placement. Cathet Cardiovasc Diagn 44: 1-6, 1998 